78 Siberian Journal of Economics and Management, Vol. 7, No 4, 2018

DOI: 10.12731/2070-7568-2018-4-78-99

УДК 338

\title{
ИНДУСТРИАЛЬНЫЕ ПАРКИ КАК ОПОРНЫЕ ТОЧКИ ФОРМИРОВАНИЯ ЭКОНОМИЧЕСКОГО КАРКАСА ИННОВАЦИОННОГО РАЗВИТИЯ ТЕРРИТОРИЙ
}

\author{
Никитаева А.Ю., Андрющенко О.Г.
}

Статья посвящчена исследованию индустриальных парков как опорных точек экономического каркаса инновачионного развития территорий.

В качестве методологической основы исследования использованы в комплексе системный, синергетический, институциональный, эволючионный, эндогенный подходы. В качестве теоретической базы работы выступили конщепџия экономического каркаса региона, концепциия интеграционного развития промылиленности, неоиндустриальная парадигма экономического развития. Методический апnарат статьи представлен методами анализа, синтеза, абстрагирования, логического обобщения.

Целью работы является определение лимитирующих факторов и приоритетных направлений развития индустриальных парков для обеспечения позитивной инновачионной динамики, повышения эффективности деятельности промышленных компаний и социально-экономического развития региональных хозяйственных систем.

Результаты работы: дана характеристика индустриальных парков и их роли как опорных точек экономического каркаса инновациионого развития территорий; эмпирически проиллюстрированы низкие результаты инновационной деятельности в отечественной экономике; раскрыты причины ограниченной результативности и определены предпосылки успешного развития индустриальных парков в России; обоснована иелесообразность создания «умных индустриальных парков». 
Выводы: потенцииально высокая эффективность индустриальных парков в контексте обеспечения стимулов для инновачионного развития территорий и выстраивания устойчивого экономического каркаса пока не получила достаточной реализачии в современных российских условиях. В настоящее время развитие индустриальных парков должно быть связано не только с повышением обоснованности их создания на региональном уровне и формированием эффективной системы менеджмента на уровне хозяйствующих субъектов, но и учетом мировых технологических трендов и особенностей развития аналогичных структур, проявляющихся 8 усилении роли информационного обмена, распространении моделей «умныху и экоиндустриальных парков».

Область применения результатов: результаты исследования могут быть использованы при обосновании приоритетов и мер государственной инновационной, пространственной и промышленной политики, разработке концепций, стратегий и программ развития индустриальных парков на мезо- и микроуровне в условиях цицровизации экономики.

Ключевые слова: индустриальный парк; инновационное развитие территорий; модернизация промышленности; экономический каркас.

\section{NDUSTRIAL PARKS AS A REFERENCE POINT OF FORMATION OF THE ECONOMIC FRAMEWORK OF INNOVATIVE DEVELOPMENT OF TERRITORIES}

\section{Nikitaeva A.Y., Andryushchenko O.G.}

The article is devoted to the study of industrial parks as reference points of the economic framework of innovative development of territories.

Methodology: The complex of system, synergy, institutional, evolutionary, and endogenous approaches is used as a methodological basis of research. The concept of the economic framework of 
the region, the concept of integration development of industry, neoindustrial paradigm of economic development were taken as theoretical platform of research. Methodological apparatus of the article is presented by methods of the analysis, synthesis, abstraction, logical generalization.

Purpose of the paper is to determine the limiting factors and priority directions of development of industrial parks to ensure positive innovation dynamics, improve the efficiency of industrial companies and socio-economic development of regional economic systems.

Results: the characteristic of industrial parks and their role as reference points of economic framework of innovative development of territories is given; low results of innovative activity in domestic economy are empirically illustrated; the reasons of limited efficiency are revealed and preconditions of successful development of industrial parks in Russia are defined; expediency of creation of "smart industrial parks» is proved.

Conclusion: the potentially high efficiency of industrial parks in the context of providing incentives for innovative development of territories and building a sustainable economic framework has not yet received sufficient implementation in modern Russian conditions. At present, the development of industrial parks should be associated not only with increasing the validity of their creation at the regional level and the formation of an effective management system at the level of economic entities, but also taking into account the global technological trends and features of the development of similar structures, manifested in the strengthening of the role of information exchange, the spread of models of "smart" and eco-industrial parks.

Practical implications: the results of the study can be used in the justification of the priorities and measures of the state innovation, spatial and industrial policy, the development of concepts, strategies and programs for the development of industrial parks at the meso-and micro-level in the context of digitalization of the economy.

Keywords: industrial Park; innovative development of territories; industrial modernization; economic framework. 


\section{Введение}

В современных российских условиях сложилась ситуация, когда наблюдается высокая дифференциация уровня социально-экономического развития региональных экономических систем, причем как с позиции межрегионального сопоставления, так и с точки зрения внутрирегиональных показателей, характеризующих центральные и периферийные территории [4]. Одновременно подавляющее большинство регионов страны (регион в данной работе рассматривается синонимично с субъектом РФ, что позволяет отразить его понимание как части территории РФ, обладающей целостностью хозяйства, общностью природных, социально-экономических, институциональных, национально-культурных условий, специфическим характером воспроизводственного процесса, а также наличием административных органов управления) характеризуется дотационностью бюджетов, низким уровнем инновационности, невысоким уровнем технологического развития промышленности, высоким уровнем износа основных фондов [15]. При этом следует принимать во внимание тот факт, что в глобальной экономике в рамках происходящей новой промышленной революции и сопряженного с ней перехода в фазу роста нового технологического уклада именно способность к коммерциализации достижений научно-технического прогресса и инновационной модернизации экономики, гармонизированной с новыми индустриальными трендами, становится решающим фактором конкурентоспособности. Учитывая одновременно территориальную локализацию инноваций даже в глобальной среде [32], важность географической близости субъектов инновационной деятельности [26], усиление роли именно регионов в конкуренции на мировой арене [21], сложившаяся ситуация является крайне неблагоприятной. В этой связи актуализируется поиск концептуальной платформы и ключевых факторов системной активизации инновационного развития территорий. С точки зрения авторов, решение данной задачи возможно через конвергенцию концепции создания регионального экономического каркаса и концепции интеграционного развития промышленности. 
Формирование концепции регионального экономического каркаса в отечественной научной литературе происходило с середины прошлого века, начиная с работ Н.Н. Баранского, говорящего о каркасе как об «остове, который формирует территорию, придает ей определенную конфигурацию» [3], и получило заметное развитие в последние годы благодаря работам А.К. Доргушаовой, Л.Г. Матвеевой, О.А. Черновой и других исследователей $[7,29,34]$.

В современной научной литературе экономический каркас региона рассматривается как совокупность взаимоувязанных территориальных подсистем, функционирование которых обеспечивает определенную организацию и структуризацию регионального пространства, способствуя его целостности $[7,34]$. При этом качество каркаса, его устойчивость определяется опорными точками (некоторыми узлами), в роли которого выступают интегрированные структуры различных типов, формирующие при условии согласованного взаимодействия каркасные матрицы, имеющие критический потенциал аккумулирования ресурсов для реализации инновационной деятельности в регионе [7, 29]. К числу таких структур традиционно относят кластеры, сети, крупные интегрированные промышленные структуры, индустриальные зоны и парки, функционирование которых позволяет создать точки сверхконцентрации индустриально-инновационного потенциала в экономическом пространстве и обеспечить экономический рост [20]. Однако в современных российских условиях такие структуры зачастую обладают высоким ресурсным потенциалом, делающим возможным их успешное функционирование без заметного увеличения показателей инновационной деятельности в регионах размещения при отсутствии сильного конкурентного давления.

Как показывает опыт реализации кластерной политики в России $[12,19]$, формирование промышленных кластеров, в том числе, с привлечением ресурсов государственных программ поддержки, не привело к существенному увеличению показателей инновационной деятельности в регионах страны или установлению устойчивой позитивной динамики в данной сфере (рис. 1). 
В свою очередь, под интеграционным развитием промышленности в данной работе понимается развитие на базе расширения технологий интеграции предприятий, когда в качестве одного из ключевых драйверов промышленного роста и повышения конкурентоспособности рассматривается формирование партнерских структур с интегрированными бизнес-процессами, создание кроссотраслевых межфирменных сетей, инновационных промышленных кластеров, государственно-частных партнерств, индустриальных парков и других форм интеграции хозяйствующих субъектов.

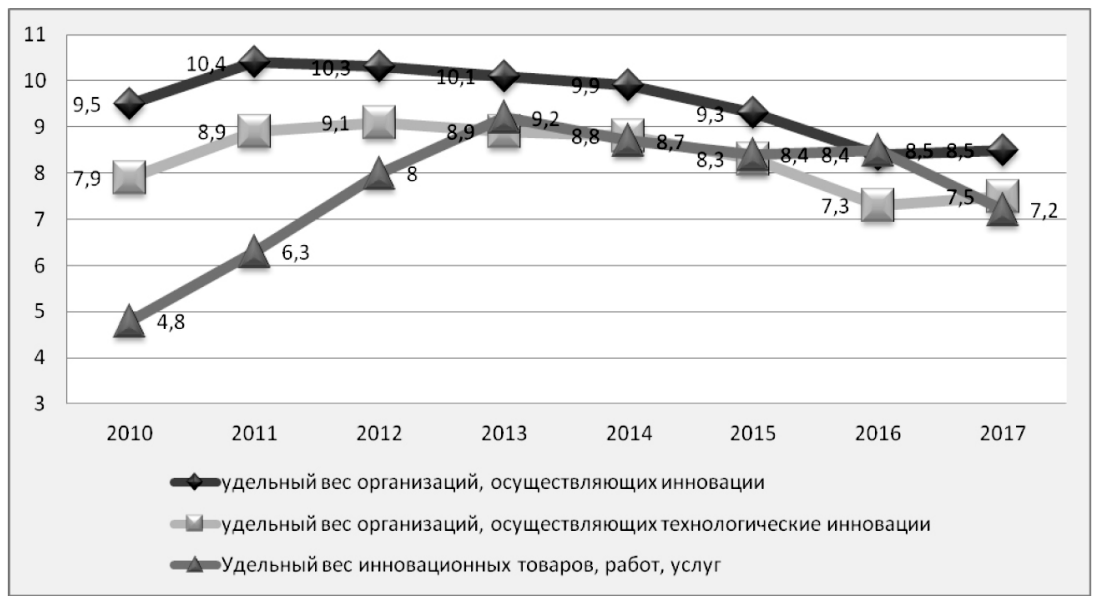

Рис. 1. Характеристики инновационной деятельности в России, \% [17]

При этом интеграция рассматривается не как жесткое вертикальное или горизонтальное объединение предприятий в юридическом смысле, а как расширение партнерского сегмента отношений организаций в рыночной среде, объединение потенциала и институциональных ресурсов предприятий, взаимная адаптация, углубление партнерских отношений с целью получения синергетического эффекта за счет сочетания кооперационных и конкурентных отношений хозяйствующих субъектов. Исследования в русле данного тематического направления получили большое распространение в российской и зарубежной экономической науке $[1,2,5,6,9,19,24$, 
$25,28,31,33,36,37-43]$. Существенное внимание уделено изучению конкретных интегрированных организационных структур и индустриальному симбиозу $[1,19,26,38]$. Особая роль в инновационном развитии регионов при этом отводится индустриальным паркам [10, 14, 18, 31, 37, 39]. В современных публикациях раскрыты их виды, особенности функционирования, организационные модели $[8,11$, $13,14,16,18,22,27]$.

При этом представляется целесообразным отметить, что результативность индустриальных парков как структур, потенциально обеспечивающих более активное формирование экономического каркаса за счет различных моделей интеграции, остается на невысоком уровне в современных российских условиях. С учетом этого, представляется целесообразным сконцентрировать внимание на вопросах развития индустриальных парков как потенциальных узлах экономического каркаса, которые по своей сути являются объектами инновационной инфраструктуры и способы создать благоприятные условия для инноватизации промышленности на мезоуровне. Это определило целевой фокус данной работы на определение лимитирующих факторов и приоритетных направлений развития индустриальных парков в контексте формирования экономического каркаса территорий для решения задачи сбалансированного инновационного развития регионов страны.

\section{Индустриальные парки и их роль в инновационном развитии территорий}

«Индустриальный парк - это специально организованная для размещения новых производств территория, обеспеченная энергоносителями, инфраструктурой, необходимыми административно-правовыми условиями, управляемая специализированной компанией» [16]. Индустриальные парки потенциально обладают значительным количеством преимуществ за счет интеграционных эффектов, содействия росту производительности труда, инновационности, устойчивости организаций, развития партнерских связей, роста связанности региональных экономик, достижения баланса интере- 
сов и объединению ресурсов государства и бизнеса и т.д. При этом индустриальные парки обеспечивают эффекты как непосредственно в сфере повышения эффективности деятельности промышленных компаний, в первую очередь, за счет эффекта локализации, так и для территорий за счет эффекта урбанизации, развития рынка труда, распределения нагрузки на поддержание инфраструктуры на больший круг компаний, привлечения новых инвесторов на территорию [22], совместного использования ресурсов [43]. Более того, как отмечает А.А. Плеслов, за счет развития индустриальных парков «фактически создается инфраструктурная база реиндустриализации страны в рамках стратегии пространственного развития Российской Федерации» [18], что свидетельствует о важной роли указанных структур как опорных точек в формировании экономического каркаса регионального развития.

Однако в России на современном этапе индустриальные парки имеют недостаточный уровень развития (для генерирования сильного импульса инновационной динамики), низкую «заселенность» резидентами и инвестиционной привлекательностью, по оценкам исследователей, «российский рынок индустриальных парков находится в процессе формирования, а успешный старт большинства проектов остается на стадиях зарождения и проектирования» [16]. Позитивная динамика количества индустриальных парков в России (рис. 2) не привела до настоящего момента ни к заметному изменению показателей инновационной активности организаций, как показывает анализ данных, приведенных на рисунке 1, ни к увеличению доли затрат на технологические инновации (рис. 3).

\section{Ограничения и возможные приоритеты}

\section{развития индустриальных парков как опорных элементов экономического каркаса}

В определенной степени на сложившуюся ситуацию повлияло неравномерное распределение индустриальных парков по территории страны, более половины подобных структур сконцентрирова- 
но всего в двух федеральных округах - Центральном федеральном округе и Приволжском федеральном округе [23]. Наряду с этим, можно выделить две группы причин, лимитирующих развитие индустриальных парков в России. Во-первых, речь идет об инерционности хозяйственной системы и непродолжительном периоде развития индустриальных парков, значительное количество которых находится на стадиях создания, проектирования или фиксации намерений. Во-вторых, о зачастую узком понимании сущности и содержания деятельности индустриальных парков, что осложняет создание адекватных институциональных, инвестиционных, организационно-управленческих условий их развития. Об этом свидетельствуют такие выделяемые исследователями проблемы функционирования индустриальных парков, как неопределенная и заранее не проработанная концепция создания и структура резидентов, отсутствие стратегии развития, недостаточный уровень инженерной инфраструктуры, высокая стоимость земель, отдаленность рынков сбыта и т.д. [13]. Учитывая особенность индустриальных парков, их успешное создание возможно при участии региональных органов власти и институтов промышленного развития, а эффективное управление на микроуровне должно строиться на базе принципов и механизмов современного менеджмента $[11,14]$.

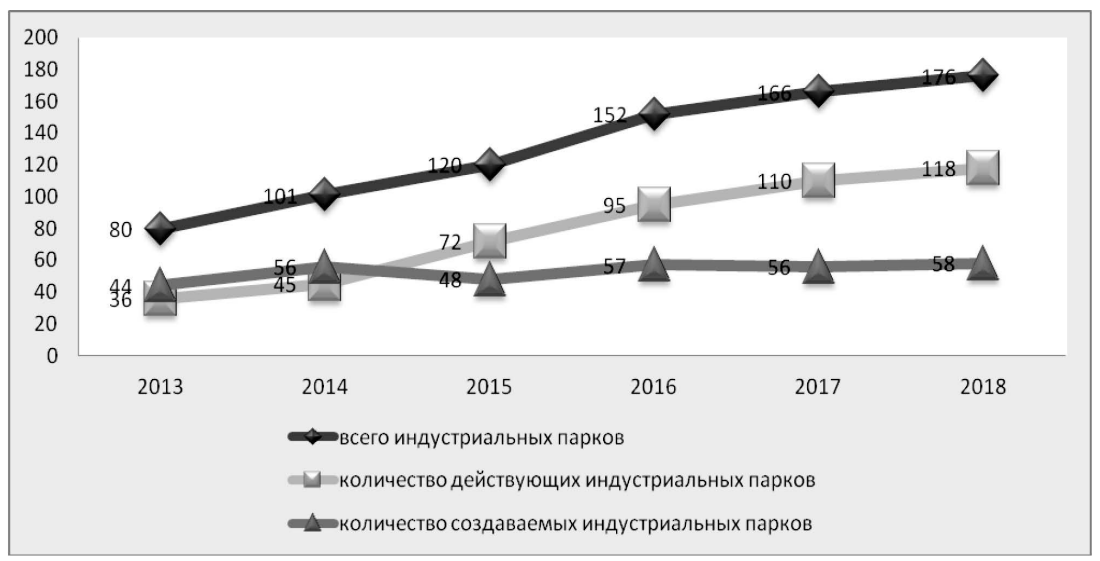

Рис. 2. Динамика создания индустриальных парков в России $[8,23]$ 


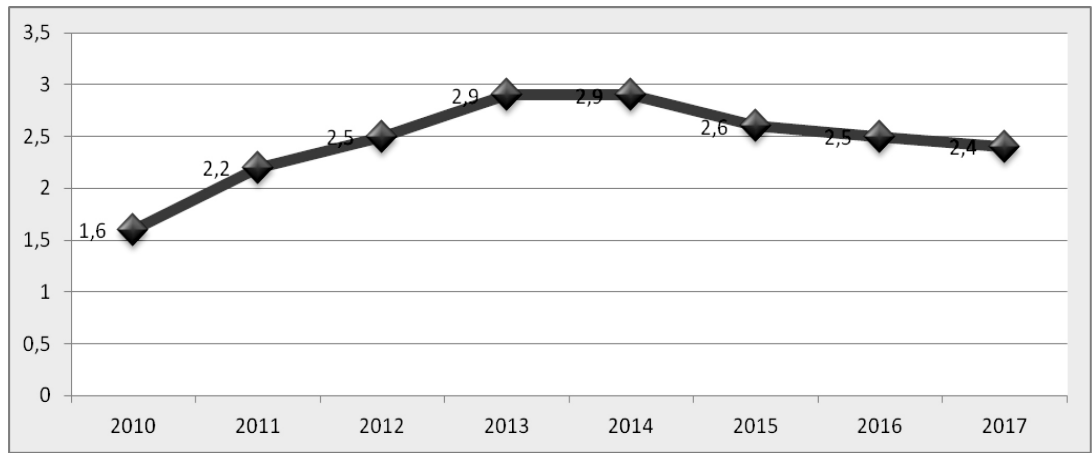

Рис. 3. Удельный вес затрат на технологические инновации в общем объеме отгруженных товаров, выполненных работ, услуг, \% [17]

Особенности управления индустриальными парками в значительной степени определяются их видами и спецификой функционирования $[10,27]$. Однако важно отметить, в условиях четвертой промышленной революции, сама концепция индустриальных парков трансформируется в направлении создания «умных» парков (англ. smart industrial parks), что предполагает масштабное использование современных цифровых разработок, виртуализиацию инфраструктурной составляющей инновационной деятельности [35], использование искусственного интеллекта, интеллектуального анализа данных, 3D-моделирования и прототипирования, автоматизации различных элементов цепочки создания стоимости. Так называемые «умные индустриальные парки» обеспечивают интеллектуальные средства поддержки управления данными структурами для смягчения воздействия на окружающую среду и снижения затрат [30]. В цифровой экономике в создании эффективных моделей индустриальных парков все большую роль играют информационный обмен и диффузия знаний, выступающие основой для успешной кооперации [38]. То есть, базовой предпосылкой эффективности моделей умных индустриальных парков является создание многоканальных схем информационного обмена между стейкхолдерами с разграничением ролей и содержания вклада в инновационный процесс со стороны различных участников на разных функциональных уровнях. Напри- 
мер, на уровне принятия решений исследовательские институты вносят инновационные идеи, центры кооперации и продвижения обеспечивают диффузию профессиональных знаний и трансфер инноваций, промышленные предприятия предлагают практический опыт, а управляющие компании - управленческий опыт. В свою очередь, региональное правительство дает информацию о приоритетах развития территорий. Тогда как на исполнительских уровнях все функциональные компоненты индустриального парка должны кооперироваться друг с другом для поддержки информационного обмена, играющего решающую роль в обеспечении эффективной деятельности таких структур [39, 40].

В русле общего тренда создания умных индустриальных парков важное направление связано также с формированием эко-индустриальных парков, предполагающих, в частности, создание умных энергетических систем, существенно расширяющих роль рассматриваемых структур одновременно с позиций устойчивости и конкурентоспособности [37, 41, 42].

\section{Выводы}

С учетом вышесказанного, можно сформулировать следующие практические рекомендации по приоритетным направлениям развития индустриальных парков в современных российских условиях:

- предварительная проработка концепции, стратегии, организационно-управленческой модели и информационной схемы взаимодействия участников индустриального парка с позиции обеспечения его конкурентоспособности и устойчивости, рассмотрение наличия указанных решений в качестве одного из критериев государственной поддержки индустриальных парков;

- согласование процессов создания индустриальных парков со стратегиями и программами цифровизации, инновационного, научно-технологического и территориального развития субъектов РФ; 
- создание «умных индустриальных парков» и дополнение интеллектуальными технологиями формирующихся и действующих индустриальных парков для ускорения, повышения результативности и эффективности инновационного цикла посредством использования виртуальной инфраструктуры, искусственного интеллекта, 3D-принтинга и 3D-моделирования, больших данных и т.д.;

- усиление «эко» составляющей индустриальных парков, в первую очередь, в части повышения эффективности совместного использования ресурсов, выбора энергоэффективных моделей за счет применения информационно-коммуникационных и аналитических технологий.

Таким образом, индустриальные парки играют важную роль одновременно в решении целого комплекса вопросов активизации инновационной деятельности на региональном уровне. При этом важно учитывать, что при рассмотрении индустриальных парков не только с точки зрения непосредственного создания условий для улучшения показателей инновационной деятельности их участников, но и с позиции их вклада в формирование каркасной матрицы территориального развития, размещение и поддержка развития данных структур должны синхронизироваться с региональными стратегиями и программами социально-экономического развития. Одним из наиболее важных направлений развития индустриальных парков в условиях цифровизации экономики является развитие информационного обмена для формирования устойчивых кооперационных отношений стейкхолдеров, создание новых «умных» и экономичных бизнес-моделей, более эффективных и конкурентоспособных в современных условиях.

Статья подготовлена в Южнном федеральном университете при выполнении иницичативного научного проекта фундаментального характера «Методология и механизмы управления ресурсным обеспечением стратегического развития Юга России» в рамках реализации внутреннего гранта ЮФУ (ВнГр-07/2017-13 от 09.03.2017 г.). 


\section{Список литературы}

1. Алешин А.В., Никитаева А.Ю. Концептуальная модель межфирменного партнерства для решения актуальных проблем и модернизации экономики регионов Юга России // Journal of Economic Regulation (Вопросы регулирования экономики). Том 4. № 4. 2013. С. 34-40.

2. Байбакова Е.Ю., Клочков В.В. Экономические аспекты формирования сетевых организационных структур в российской наукоемкой промышленности // Управление большими системами: сборник трудов. 2010. № 30-1. С. 697-721.

3. Баранский Н.Н. Об экономико-географическом изучении городов // Экономическая география. Экономическая картография. М.: Географгиз. 1956. $366 \mathrm{c.}$

4. Бухвальд Е.М. Инновационное развитие регионов: роль децентрализации полномочий//Пространственная экономика. 2013. № 1. С. 55-71.

5. Вертакова Ю.В. Использование сетевого подхода для обеспечения устойчивости развития предпринимательских структур в условиях экономического кризиса // Инновационный вестник Регион. 2009. № 2. С. 36- 43.

6. Голованова С.В., Авдашева С.Б., Кадочников С.М. Межфирменная кооперация: анализ развития кластеров в России // Российский журнал менеджмента. 2010. Т. 8. № 1. С. 41-66.

7. Доргушаова А.К. Механизм формирования экономического каркаса несырьевого развития региона. Майкоп: Изд-во Майкопского технологического университета, 2016. 299 с.

8. Индустриальные парки России. Отраслевой обзор. Выпуск 5, 2017. Ассоциация индустриальных парков// http://www.indparks.ru/\%D0\% 9E\%D0\%B1\%D0\%B7\%D0\%BE\%D1\%80\%202017\%20for\%20site.pdf

9. Котляров И.Д. Нетипичные формы организации хозяйственной деятельности // Экономическая наука современной России. 2017. № 1. С. $22-40$.

10. Крайнова А.Э. Рассмотрение места индустриальных парков и их роли в инновационном развитии экономики // Вестник ГУУ. 2014. №14. С. 51-55.

11. Мазников И.А. Индустриальный парк: опыт создания и проблемы управления // Актуальные проблемы авиации и космонавтики. 2017. №13. C. 57-60. 
12. Миндлин Ю.Б., Колпак Е.П., Балыкина Ю.Е. Проблемы использования кластеров в Российской Федерации // Вестник НГУЭУ. 2014. № 1. С. 22-32.

13. Миронов Д.С. Концептуальные основы создания и функционирования индустриальных парков // Российское предпринимательство. 2017. №20. С. 2965-2982.

14.Навроцкий Р.О., Щеглов А.А. Научно-методические подходы к формированию индустриальных парков на современном этапе: теоретический анализ // ИнноЦентр. 2015. № 1. С. 70-84.

15. Никитаева А.Ю. Институциональная структура региона в контексте инновационного развития промышленности // Journal of Institutional Studies (Журнал институциональных исследований). 2017. №1. С. 134-149.

16. Официальный сайт Российской Ассоциации индустриальных парков. URL: http://www.indparks.ru-/ru/about/info.

17. Официальный сайт Росстата РФ. Наука и инновации// http://www. $\mathrm{gks.ru} / \mathrm{wps} / \mathrm{wcm} / \mathrm{connect} / \mathrm{rosstat}$ _main/rosstat/ru/statistics/science_and innovations/science/\#

18. Плеслов А.А. Организационно-экономические факторы создания и развития индустриальных парков // Российское предпринимательство. 2017. №5. С. 749-759.

19. Плотников В.А. Риски реализации кластерной политики // Вопросы безопасности. 2015. № 2. С. 8-24.

20. Развадовская Ю.В., Ложникова А.В., Шевченко И.К. Территориально-отраслевое планирование в условиях реализации стратегий решоринга и реиндустриализации // Национальные интересы: приоритеты и безопасность. 2015. №10 (295). С. 2-10.

21. Рожков Ю.В., Чёрная И.П. Новая парадигма конкуренции регионов // Современная конкуренция. 2009. №3. С. 51-63.

22. Сандлер Д.Г., Кузнецов П.Д. Индустриальные парки в России: концептуальная проработка проектов // Экономика региона. 2015. №1. С. $76-88$.

23. Сводная статистическая информация геоинформационной системы по индустриальным паркам. Минпродторг России. https://www.gisip. $\mathrm{ru} / \mathrm{stats}$ sum $/ \mathrm{pdf} / \mathrm{ru} /$ 
24. Уильямсон О.И. Экономические институты капитализма: Фирмы, рынки, «отношенческая» контрактация. СПб.: Лениздат; CEV Press, 1996. $702 \mathrm{c}$.

25. Устюжанина Е.В. Формы интеграции бизнеса: взгляд с позиции институциональной теории // Вестник Российского экономического университета им. Г.В. Плеханова. 2015. № 2. С. 34-45.

26. Фияксель Э.А., Исланкина Е.А. Глокализация инноваций: роль кластеров и международного контекста в региональном развитии//Инновации. 2015.№ 11 (205). С. 64-74.

27. Хижняков Б.П. Особенности индустриальных парков и их классификационные признаки // Социально-экономические явления и процессы. 2015. №10. С. 184-188.

28. Шерешева М.Ю. Формы сетевого взаимодействия компаний. М.: Изд. дом Гос. ун-та - Высшая школа экономики, 2010. 339 с.

29. Экономический каркас сбалансированного модернизационного развития региона: концепция и механизм формирования: монография / Под общ. ред. проф. Л.Г. Матвеевой. Ростов-на-Дону: Издательство Южного федерального университета. 2018. 280 с.

30. Ahvenniemi H., Huovila A., Pinto-Seppä I., Airaksinen M. What are the differences between sustainable and smart cities// Cities. 2017. 60, pp. 234-245.

31. Amin, A. An Institutionalist Perspective on Regional Economic Development // International Journal of Urban and Regional Research. № 23: no. 2. 1999 , pp. 365-378.

32. Benneworth P., Dassen A. Strengthening Global-Local Connectivity in Regional Innovation Strategies: Implications for Regional Innovation Policy//OECD Regional Development Working Papers. 2011/01. OECD Publishing. 2011.

33. Busom I., Fernandez-Ribas A. The impact of firm participation in R\&D programmes on R\&D partnerships // Research Policy. 37. 2008, pp. 240-257.

34. Chernova O.A., Matveeva L.G., Dorgushaova A.K., Kuizheva S.K., Zarubin V.I. Formation of a steady social and economic framework of the region // Journal of Applied Economic Sciences (JAES). 2015. №8 (38), pp. 1189-1198. 
35. Devanand A., Zhoua L., Karimia I.A., Kraft M. An Ontology Based Cyber-infrastructure for the development of Smart Eco Industrial Parks/ Proceedings of the $13^{\text {th }}$ International Symposium on Process Systems Engineering - PSE 2018, pp. 2047-2052.

36. Enright M.J. Survey on the Characterization of Regional Clusters: Initial Results. Working Paper, Institute of Economic Policy and Business Strategy: Competitiveness Program, University of Hong Kong, 2000. 21 p.

37. Gómeza A.M.M., Gonzáleza F.A., Bárcena M.M. Smart eco-industrial parks: A circular economy implementation based on industrial metabolism// Resources, Conservation \& Recycling. 135. 2018, pp. 58-69.

38. Jensen P.D., Basson L., Hellawell E.E., Bailey M.R., Leach M. Quantifying 'geographic proximity': experiences from the United Kingdom's national industrial symbiosis programme// Resources, Conservation \& Recycling. 2011. 55 (7), pp. 703-712.

39. Hein A.M., Jankovic M., Feng W., Farel R., Yune J.H., Yannou B. Stakeholder power in industrial symbioses: a stakeholder value network approach// Journal of cleaner production. 2017. 148, pp. 923-933.

40. Sa de Abreu M.C., Ceglia D., 2018. On the implementation of a circular economy: the role of institutional capacity-building through industrial symbiosis// Resources, Conservation \& Recycling. 138, pp. 99-109.

41. Simeoni P., Nardin G., Ciotti G. Planning and design of sustainable smart multi energy systems. The case of a food industrial district in Italy// Energy. 2018. 163, pp. 443-456.

42. Xianga P., Yuana T. A collaboration-driven mode for improving sustainable cooperation in smart industrial parks// Resources, Conservation \& Recycling. 2019. 141, pp. 273-283.

43. Xu F., Xiang N., Tian J., Chen L. 3es-based optimization simulation approach to support the development of an eco-industrial park with planning towards sustainability:a case study in Wuhu, China// Journal of cleaner production. 2017. 164, pp. 476-484.

\section{References}

1. Aleshin A.V., Nikitaeva A.Y. Konceptual'naya model' mezhfirmennogo partnerstva dlya resheniya aktual'nyh problem i modernizacii ehkonomiki regionov Yuga Rossii [A Conceptual model of inter-firm partnerships 
to solve current problems and economic modernization of regions of the South of Russia]. Journal of Economic Regulation. Volume 4, No. 4, 2013, pp. 34-40.

2. Baibakova E.V., Klochkov V. Ehkonomicheskie aspekty formirovaniya setevyh organizacionnyh struktur v rossijskoj naukoemkoj promyshlennosti [Economic aspects of formation of network organizational structures in the Russian science-intensive industry]. Upravlenie bol'shimi sistemami [Management of large systems]: proceedings. 2010. No. 30-1, pp. 697-721.

3. Baransky N.N. Ob ehkonomiko-geograficheskom izuchenii gorodov [On economic and geographical study of cities]. Ekonomicheskaya geografiya. Ekonomicheskaya kartografiya [Economic geography. Economic cartography]. M.: Geografgiz. 1956.

4. Buchwald E.M. Innovacionnoe razvitie regionov: rol' decentralizacii polnomochij [Innovative development of regions: the role of decentralization of powers]. Prostranstvennaya ekonomika [Spatial economy]. 2013. No. 1, pp. 55-71.

5. Vertakova Y.V. Ispol'zovanie setevogo podhoda dlya obespecheniya ustojchivosti razvitiya predprinimatel'skih struktur v usloviyah ehkonomicheskogo krizisa [The Use of network approach to ensure the sustainable development of business structures in the conditions of economic crisis]. Innovatsionnyy vestnik Region [Innovative Journal Region]. 2009. No. 2, pp. 36-43.

6. Golovanova S.V., Avdasheva S.B., Kadochnikov S.M. Mezhfirmennaya kooperaciya: analiz razvitiya klasterov v Rossii [Interfirm cooperation: an analysis of cluster development in Russia]. Rossiyskiy zhurnal menedzhmenta [Russian journal of management]. 2010. Vol. 8. No. 1, pp. 41-66.

7. Dorgushaova A.K. Mekhanizm formirovaniya ehkonomicheskogo karkasa nesyr'evogo razvitiya regiona [Mechanism of formation of an economic framework of non-raw material development of the region]. Maykop: Publishing house of the Maykop technological university, 2016.

8. Industrial'nye parki Rossii [Industrial parks of Russia]. Sector report. Issue 5, 2017. Association of industrial parks. http://www.indparks.ru/ $\% \mathrm{D} 0 \% 9 \mathrm{E} \% \mathrm{D} 0 \% \mathrm{~B} 1 \% \mathrm{D} 0 \% \mathrm{~B} 7 \% \mathrm{D} 0 \% \mathrm{BE} \% \mathrm{D} 1 \% 80 \% 202017 \% 20$ for $\% 20$ site.pdf (accessed December 15, 2018) 
9. Kotlyarov I.D. Netipichnye formy organizacii hozyajstvennoj deyatel'nosti [Atypical forms of organization of economic activity]. Ekonomicheskaya nauka sovremennoy Rossii [Economic science of modern Russia]. 2017. No. 1, pp. 22-40.

10. Kraynova A.E. Rassmotrenie mesta industrial'nyh parkov $i$ ih roli $v$ innovacionnom razvitii ehkonomiki [Consideration of the place of industrial parks and their role in innovative development of economy]. Vestnik GUU [The GUU Bulletin]. 2014. No. 14, pp. 51-55.

11. Maznikov I.A. Industrial Park: experience of creation and management problems. [Industrial Park: experience of creation and management problems]. Aktual'nye problemy aviatsii i kosmonavtiki [Actual problems of aviation and cosmonautics]. 2017. No. 13, pp. 57-60.

12. Mindlin Y.B., Kolpak E.P., Balykin Y.E. Problemy ispol'zovaniya klasterov v Rossijskoj Federacii [Problems of using clusters in the Russian Federation]. Vestnik of NSUEM. 2014. No. 1, pp. 22-32.

13. Mironov D.S. Konceptual'nye osnovy sozdaniya i funkcionirovaniya industrial'nyh parkov [Conceptual bases of creation and functioning of industrial parks]. Rossiyskoe predprinimatel'stvo [Journal of Russian entrepreneurship]. 2017. No. 20, pp. 2965-2982.

14. Nawrocki R.A., Shcheglov A.A. Nauchno-metodicheskie podhody k formirovaniyu industrial'nyh parkov na sovremennom ehtape: teoreticheskij analiz [Scientific and methodological approaches to the formation of industrial parks at the present stage: theoretical analysis]. InnoTsentr. 2015. No. 1, pp. 70-84.

15. Nikitaeva A.Y. Institucional'naya struktura regiona v kontekste innovacionnogo razvitiya promyshlennosti [Institutional structure of the region in the context of innovative development of industry]. Journal of Institutional Studies. 2017. 1, pp. 134-149.

16. Oficial'nyj sajt Rossijskoj Associacii industrial'nyh parkov [Official website of the Russian Association of industrial parks]. http:/www.indparks.ru-/ru/about/info (accessed December 15, 2018).

17. Oficial'nyj sajt Rosstata RF. Nauka i innovacii [Official website of Rosstat. Science and innovation]. http://www.gks.ru/wps/wcm/connect/rosstat_main/rosstat/ru/statistics/science_and_innovations/science/\# (accessed December 1, 2018). 
18. Pleslov A.A. Organizacionno-ehkonomicheskie faktory sozdaniya i razvitiya industrial'nyh parkov [Organizational-economic factors of creation and development of industrial parks]. Rossiyskoe predprinimatel'stvo [Journal of Russian entrepreneurship]. 2017. No. 5, pp. 749-759.

19. Plotnikov V.A. Riski realizacii klasternoj politiki [Risks in the implementation of the cluster policy]. Voprosy bezopasnosti [Security Issues]. 2015. No. 2, pp. 8-24.

20. Razvadovskaya Y.V., Lozhnikova V.A., Shevchenko I.K. Territorial'no-otraslevoe planirovanie $v$ usloviyah realizacii strategij reshoringa i reindustrializacii [Territorial-branch planning in terms of the implementation of reshoring and reindustrialization strategies]. Natsional 'nye interesy: prioritety i bezopasnost' [National interests: priorities and security]. 2015. №10 (295), pp. 2-10.

21. Rozhkov Y.V., Black I.P. Novaya paradigma konkurencii regionov [A New paradigm of the regions' competition]. Sovremennaya konkurentsiya [Modern competition]. 2009. No. 3, pp. 51-63.

22. Sandler D.G., Kuznetsov P.D. Industrial'nye parki v Rossii: konceptual'naya prorabotka proektov [Industrial parks in Russia: conceptual dvelopment of projects]. Ekonomika regiona [Economy of region]. 2015. No. 1, pp. 76-88.

23. Svodnaya statisticheskaya informaciya geoinformacionnoj sistemy po industrial'nym parkam [Summary statistical information of the geographic information system for industrial parks]. Minprodtorg Of Russia https://www.gisip.ru/stats_sum/pdf/ru/ (accessed December 10, 2018).

24. Williamson O.I. Ehkonomicheskie instituty kapitalizma: Firmy, rynki, «otnoshencheskaya» kontraktaciya [Economic institutions of capitalism: Firms, markets, "relational" contracting]. SPb.: Lenizdat; CEV Press, 1996. $702 \mathrm{p}$.

25. Ustyuzhanina E.V. Formy integracii biznesa: vzglyad s pozicii institucional'noj teorii [Forms of business integration: a view from the position of institutional theory]. Vestnik Rossiyskogo ekonomicheskogo universiteta im. G.V. Plekhanova [Herald of the Russian University of Economics named by G.V. Plekhanov]. 2015. No. 2, pp. 34-45. 
26. Fiyaksel E.A., Islankina E.F. Glokalizaciya innovacij: rol' klasterov i mezhdunarodnogo konteksta $\mathrm{v}$ regional'nom razvitii [Glocalization of innovations: the role of clusters and transnational context in regional development]. Innovatsii [Innovations]. 2015. No 11 (205), pp. 64-74.

27. Khizhnyakov B.P. Osobennosti industrial'nyh parkov $i$ ih klassifikacionnye priznaki [Characteristics of industrial parks and their classification features]. Sotsial'no-ekonomicheskie yavleniya i protsessy [Socio-economic phenomena and processes]. 2015. No. 10, pp. 184-188.

28. Sheresheva M. Formy setevogo vzaimodejstviya kompanij [Forms of network interaction of companies]. M. Publishing house of Un. Higher school of Economics. 2010. 339 p.

29. Ehkonomicheskij karkas sbalansirovannogo modernizacionnogo razvitiya regiona: koncepciya i mekhanizm formirovaniya [The economic framework of the balanced modernization development of the region: the concept and mechanism of formation]. monograph /edited by Professor L.G. Matveeva. Rostov-on-don: Publishing house of Southern Federal University. 2018. 280 p.

30. Ahvenniemi H., Huovila A., Pinto-Seppä I., Airaksinen M. What are the differences between sustainable and smart cities. Cities. 2017. 60, pp. 234-245.

31. Amin A. An Institutionalist Perspective on Regional Economic Development. International Journal of Urban and Regional Research. № 23: no. 2. 1999 , pp. 365-378.

32. Benneworth P., Dassen A. Strengthening Global-Local Connectivity in Regional Innovation Strategies: Implications for Regional Innovation Policy. OECD Regional Development Working Papers. 2011/01. OECD Publishing. 2011.

33. Busom I., Fernandez-Ribas A. The impact of firm participation in R\&D programmes on R\&D partnerships. Research Policy. 37. 2008, pp. 240-257.

34. Chernova O.A., Matveeva L.G., Dorgushaova A.K., Kuizheva S.K., Zarubin V.I. Formation of a steady social and economic framework of the region. Journal of Applied Economic Sciences (JAES). 2015. №8 (38), pp. 1189-1198.

35. Devanand A., Zhoua L., Karimia I.A., Kraft M. An Ontology Based Cyber-infrastructure for the development of Smart Eco Industrial Parks/ 
Proceedings of the $13^{\text {th }}$ International Symposium on Process Systems Engineering - PSE 2018, pp. 2047-2052.

36. Enright M.J. Survey on the Characterization of Regional Clusters: Initial Results. Working Paper, Institute of Economic Policy and Business Strategy: Competitiveness Program, University of Hong Kong, 2000. 21 p.

37. Gómeza A.M.M., Gonzáleza F.A., Bárcena M.M. Smart eco-industrial parks: A circular economy implementation based on industrial metabolism. Resources, Conservation \& Recycling. 135. 2018, pp. 58-69.

38. Jensen P.D., Basson L., Hellawell E.E., Bailey M.R., Leach M. Quantifying 'geographic proximity': experiences from the United Kingdom's national industrial symbiosis programme. Resources, Conservation \& Recycling. 2011.55 (7), pp. 703-712.

39. Hein A.M., Jankovic M., Feng W., Farel R., Yune J.H., Yannou B. Stakeholder power in industrial symbioses: a stakeholder value network approach. Journal of cleaner production. 2017. 148, pp. 923-933.

40. Sa de Abreu, M.C., Ceglia, D., 2018. On the implementation of a circular economy: the role of institutional capacity-building through industrial symbiosis. Resources, Conservation \& Recycling. 138, pp. 99-109.

41. Simeoni P., Nardin G., Ciotti G. Planning and design of sustainable smart multi energy systems. The case of a food industrial district in Italy. Energy. 2018. 163, pp. 443-456.

42. Xianga P., Yuana T. A collaboration-driven mode for improving sustainable cooperation in smart industrial parks. Resources, Conservation \& Recycling. 2019. 141, pp. 273-283.

43. Xu F., Xiang N., Tian J., Chen L. 3es-based optimization simulation approach to support the development of an eco-industrial park with planning towards sustainability:a case study in Wuhu, China. Journal of cleaner production. 2017. 164, pp. 476-484.

\section{ДАННЫЕ ОБ АВТОРАХ}

Никитаева Анастасия Юрьевна, заведующая кафедрой информационной экономики экономического факультета, доктор экономических наук, профессор Южный федеральньй университет 
ул. Большая Садовая, 105/42, г. Ростов-на-Дону, Российская Федерачия

aunikitaeva@sfedu.ru

Андрющенко Ольга Геннадьевна, заведующая кафедрой экономики, доктор экономических наук, профессор

Новочеркасский инженерно-мелиоративный институт Донского ГАУ

ул. Пушкинская, 111, г. Новочеркасск, Ростовская область, 346428, Российская Федераџия

s0067@yandex.ru

\section{DATA ABOUT THE AUTHORS}

Nikitaeva Anastasiya Yurievna, Chair of the Department of Information Economics, Grand Ph.D. in Economics, Professor

Southern Federal University

105/42, Bol'shaya Sadovaya str., Rostov-on-Don, Russian Federation

aunikitaeva@sfedu.ru

SPIN-code: 9468-3663

ORCID: 0000-0003-0406-7440

ResearcherID: B-5056-2016

Scopus Author ID: 57090750400

Andryushchenko Olga Gennadievna, Chair of the Department of Information Economics, Grand Ph.D. in Economics, Professor Novocherkassk Engineering-Land Reclamation Institute of Don State Agrarian University 111, Pushkinskaya str., Novocherkassk, Rostov Region, 346428, Russian Federation s0067@yandex.ru SPIN-code: 2182-4696 ORCID: 0000-0003-2784-5671 Scopus Author ID: 57192306469 